\title{
AS FORMIGAS-CORTADEIRAS NA CONCEPÇÃO DE PRODUTORES RURAIS DE ALEGRE, ES
}

\author{
Pedro Henrique Charpinel Giestas ${ }^{1}$ \\ João Otávio da Silva Malaquias ${ }^{2}$ \\ Fabrícia Gonçalves Lacerda ${ }^{3}$
}

\begin{abstract}
Resumo: As formigas-cortadeiras são consideradas pragas severas da agricultura e trazem grandes prejuízos aos produtores rurais. Dessa forma, este trabalho visou realizar um estudo de caráter etnoentomológico sobre formigas-cortadeiras entre produtores rurais do município de Alegre, Espírito Santo, para avaliar o nível de conhecimento e de conscientização sobre esse problema. Foram entrevistados 100 produtores rurais por meio de questionários. Os níveis de escolaridade Ensino Superior Incompleto, Ensino Superior Completo e Ensino Médio Completo apresentaram na maioria das questões uma maior conscientização sobre as cortadeiras quando interrogados. Dentre os métodos de controle de cortadeiras, o emprego de inseticidas químicos foi o mais mencionado em todos os níveis escolares, em destaque para as iscas granuladas que foi mais citada por todos os grupos de escolaridade. Em relação à fonte do conhecimento sobre as formigas-cortadeiras, a resposta mais frequente refere-se aos conhecimentos que são repassados de geração a geração, não tendo relação com o que é aprendido em escolas ou faculdades.
\end{abstract}

Palavras-chave: Conscientização, Escolaridade, Etnoentomologia.

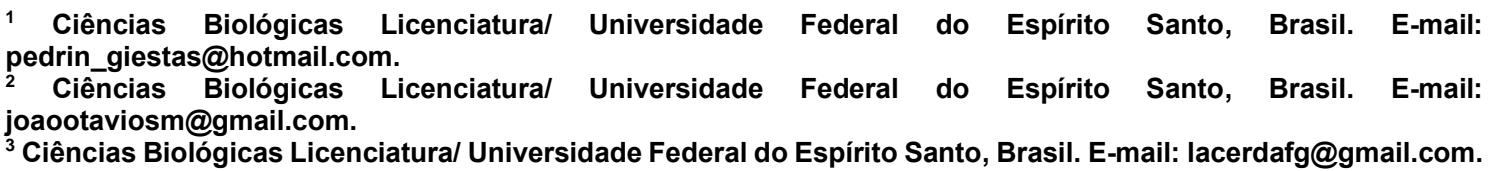

